\title{
Endoscopic injection therapy to prevent rebleeding from peptic ulcers with a protruding vessel: a controlled comparative trial
}

\author{
P Rutgeerts, A M Gevers, M Hiele, L Broeckaert, G Vantrappen
}

\begin{abstract}
Seventy five patients with severely bleeding peptic ulcer were included in a controlled comparative trial to assess the efficacy and safety of endoscopic injection therapy in preventing rebleeding from peptic ulcers that presented at endoscopy with a protruding vessel. Twenty five patients were treated with injection of epinephrine followed by polidocanol, 25 were treated with injection of absolute alcohol, and 25 with sham injection. Rebleeding occurred in $44 \%$ of patients in the sham group, $40 \%$ of those treated with epinephrine and polidocanol, and in $20 \%$ of those treated with absolute ethanol. The difference in the haemostasis rate between the control and ethanol treated subjects nearly reached significance $(p=0 \cdot 07)$. A second therapy session resulted in haemostasis rates of $68 \%$ in the epinephrine-polidocanol group and of $88 \%$ in the absolute ethanol group. These rates after two treatments as well as the emergency surgery rates $(32 \%$ in the epinephrine-polidocanol group and $8 \%$ in the absolute ethanol group; $\mathbf{p}=0.07$ ) were not significantly different. In eight of the 11 patients with rebleeding in the sham treatment group, definitive haemostasis was achieved by elective injection therapy. Overall transfusion requirements were mean (SD) $6.0(0 \cdot 7)$ units in the sham group, $6.0(0.9)$ in the epinephrinepolidocanol group, and $3.9(0.5)$ in the absolute ethanol group. Only the difference between ethanol and sham was significant $(p=0.02)$. This study shows that injection with absolute ethanol reduces rebleeding in these patients and significantly lowers transfusion requirements. Absolute ethanol was superior to epinephrine-polidocanol, which was not significantly better than sham therapy. (Gut 1993; 34: 348-350)
\end{abstract}

Department of

Medicine, Division of Gastroenterology, University Hospital Gasthuisberg, Leuven, Belgium

P Rutgeerts

A $M$ Gevers

$M$ Hiele

L Broeckaert

G Vantrappen

Correspondence to:

Dr P Rutgeerts, Professor of Medicine, Department of Gastroenterology, University Hospital Gasthuisberg, Herestraat 49, 3000 Leuven, Herestraa
Belgium.

Accepted for publication 20 August 1992
Injection therapy for bleeding peptic ulcer is attractive because it is both simple and cheap. Various solutions are used for injection, including epinephrine 1:10 000, polidocanol $1 \%$, absolute ethanol, 5\% ethanolamine, and thrombin. In addition, the injected volumes are not standardised.

Sham-controlled trials using epinephrine injection,' epinephrine-polidocanol injection, ${ }^{2-4}$ ethanol injection, ${ }^{5}$ and epinephrine-ethanolamine $^{6.7}$ have shown the benefit of endoscopic injection in preventing continued or recurrent bleeding from peptic ulcers and thereby avoiding emergency surgery. The ideal solution for injection, however, has yet to be defined, how- ever, as different forms of injection therapy have not been compared adequately.

The stigmata of recent haemorrhage predict rebleeding. One of the most reliable signs is the presence of a protruding vessel in the ulcer crater - a sign that carries a $50 \%$ chance of rebleeding. ${ }^{.}$ This subgroup of patients, therefore, is suitable for studying the efficacy of different treatments for preventing rebleeding. This study aimed to compare injection of epinephrine-polidocanol with that of absolute ethanol in the prevention of rebleeding from peptic ulcers with non-bleeding visible vessel in a controlled comparative trial. The major end point of the study was the recurrence of bleeding.

\section{Methods}

PATIENTS

All patients with acute upper gastrointestinal bleeding seen between January 1989 and June 1991 underwent diagnostic upper gastrointestinal endoscopy within 12 hours of hospital admission. The endoscopies were performed by one of four (PR, AG, MH, LB) experienced endoscopists. Patients who presented at endoscopy with a gastric, duodenal, or anastomotic ulcer with a central non-bleeding visible vessel were included in the trial. The criteria of Storey and Swain $^{89}$ were used for the identification of a visible vessel - that is a raised, red or blue spot resistant to gentle washing in the ulcer crater.

\section{RANDOMISATION}

Randomisation was carried out during endoscopy and was done in series of five patients for each trial arm. The treatment given depended on what was indicated on a card inside a sealed envelope. On the basis of the statistical assumption of $50 \%$ rebleeding rate, the aim was to include at least 20 patients per treatment group in order to detect an $80 \%$ change in response with a $0 \cdot 2$ chance of a type II error. ${ }^{\prime \prime} \mathrm{A}$ sample size of 25 in each group was calculated to detect a change in response of $75 \%$ with a power of $80 \%$. Informed consent was obtained from the patients or their family.

\section{METHOD OF HAEMOSTASIS}

Epinephrine-polidocanol

Two $\mathrm{ml}$ of epinephrine 1:10 000 were injected submucosally in each quadrant of the edge of small ulcers up to a total of $8-10 \mathrm{ml}$. For large ulcers, the solution was injected directly into the 
ulcer base around the non-bleeding visible vessel. After this pretreatment with epinephrine $1: 10000,5 \times 1 \mathrm{ml}$ of polidocanol $1 \%$ (Aethoxysclerol, Kreussler, Germany) was injected directly into the vessel site.

\section{Absolute ethanol}

Absolute dehydrated (98\%) ethanol was injected using a $1 \mathrm{ml}$ tuberculin syringe in $0.1 \mathrm{ml}$ aliquots directly at the vessel site. For safety reasons a total volume of $1 \mathrm{ml}$ was not exceeded.

\section{FOLLOW UP AFTER TREATMENT}

The lesion was observed for at least 5 minutes after injection to detect any further bleeding. Subsequent clinical follow up was carried out by clinicians not involved in the endoscopic treatment programme. They were not informed about the treatment the patients had received. Transfusion was individualised and all patients were treated with $\mathrm{H}_{2}$ antagonists. The total amounts transfused throughout the stay in hospital were carefully recorded. All patients were kept in hospital for at least 1 week and underwent an endoscopy before discharge home to ascertain that the ulcer base was clear. A clinical suspicion of rebleeding was always followed by repeat upper gastrointestinal endoscopy. Ulcers that rebled were always treated a second time with the same type of treatment used initially. A second recurrence was always an indication for emergency surgery. Patients with a non-bleeding visible vessel included in the control group who rebled dropped out and were managed either by endoscopy, or if the bleeding could not be treated endoscopically, by surgery.

\section{STATISTICAL METHODS}

The statistical significance of cross tabulation table data was evaluated by $\chi^{2}$ tests or Fisher's exact tests in case of insufficient cell frequencies. Because transfusion requirement data were not

TABLE I Patient characteristics in the three treatment groups

\begin{tabular}{llll}
\hline & Sham $(n=25)$ & $\begin{array}{l}\text { Epinephrine+ } \\
\text { polidocanol } \\
(n=25)\end{array}$ & $\begin{array}{l}\text { Absolute alcohol } \\
(n=25)\end{array}$ \\
\hline Male/female & $15 / 10$ & $16 / 9$ & $17 / 8$ \\
Mean age (range)(y) & $62(25-95)$ & $60(25-96)$ & $66(29-88)$ \\
Gastric/duodenal/anastomotic & $12 / 13 / 0$ & $13 / 12 / 0$ & $16 / 8 / 1$ \\
Actual shock & 5 & 10 & 7 \\
NSAIDs intake & 17 & 14 & 13 \\
Severe underlying disease & 7 & 9 & 7 \\
\hline
\end{tabular}

NSAIDs $=$ non-steroidal anti-inflammatory drugs.

TABLE II Endoscopic haemostasis results in the three treatment groups

\begin{tabular}{llll}
\hline & $\operatorname{Sham}(n=25)$ & $\begin{array}{l}\text { Epinephrine+ } \\
\text { polidocanol } \\
(n=25)\end{array}$ & $\begin{array}{l}\text { Absolute alcohol } \\
(n=25)\end{array}$ \\
\hline $\begin{array}{l}\text { Rebleeding (\%) } \\
\text { Definitive haemostasis (\%) after }\end{array}$ & $11(44)$ & $10(40)$ & $5(20)^{\star}$ \\
$\begin{array}{l}\text { 2 sessions } \\
\begin{array}{l}\text { Total blood transfused (mean } \\
\text { (SEM))(u) }\end{array}\end{array}$ & - & $17(68)$ & $22(88)$ \\
$\begin{array}{l}\text { Emergency surgery } \\
\text { Mortality }\end{array}$ & $6 \cdot 0(0 \cdot 7)$ & $6 \cdot 0(0 \cdot 9) \mathrm{NS}$ & $\begin{array}{l}3 \cdot 9(0 \cdot 5) \dagger \\
2 \ddagger^{\star \star}\end{array}$ \\
\hline
\end{tabular}

${ }^{\star} \mathrm{p}=0.07 v$ sham $; \mathrm{p}=0.02 v$ sham; $\neq \mathrm{p}=0.07$ (Fisher's exact) ethanol $v$ epinephrine-polidocanol; $\star \mathrm{p}=0.07 v$ sham; $\dagger \mathrm{p}=0.02 v$ sham; $\neq \mathrm{p}=0.07$ (Fisher's exact) ethanol $v$ epinephrine-polidocanol;
$\int$ Eight patients were controlled by elective injection; ${ }^{\star}$ one patient died before surgery could be carried out normally distributed, overall analysis was carried out using the Wilcoxon rank sum test, a nonparametric test for comparison of groups.

\section{Results}

During the study period, 648 patients underwent upper gastrointestinal endoscopy for gastrointestinal bleeding. At diagnostic endoscopy 75 had ulcers with non-bleeding visible vessels accessible to endoscopic therapy and were treated. The patients' characteristics are summarised in Table I. Two patients in the sham group died early after endoscopy because of underlying disease. One patient in the alcohol group had a cardia ulcer that was probably the result of a Mallory Weiss tear. It should be noted that more patients in the epinephrine-polidocanol group were admitted to hospital in shock than in the other groups. Injection of ethanol reduced the bleeding recurrence rate but this did not achieve significance. Total transfusion requirements were significantly lowered with ethanol (Table II). Injection of epinephrinepolidocanol was not significantly better than sham treatment. Although a trend towards significance was present injection of absolute ethanol was not statistically better than epinephrine-polidocanol injection in preventing a first recurrence of bleeding.

\section{FURTHER MANAGEMENT OF THE PATIENTS AT} REBLEEDING

Eight of the 11 patients who rebled after sham therapy were controlled by further elective injection therapy with epinephrine-polidocanol at the second endoscopy. Of the 10 patients who rebled in the epinephrine-polidocanol group, only two could be managed by a second therapy session whereas two of the five patients who rebled in the absolute ethanol group were controlled by repeated injection. Eventually three patients in the sham group, two in the ethanol group, and eight in the epinephrinepolidocanol group were operated on. The differences between the ethanol and epinephrinepolidocanol groups were not significant but the difference was borderline. Four patients in the sham group, four in the epinephrine-polidocanol group, and one in the absolute ethanol group died; so total mortality was nine of 75 patients or $12 \%$. Injection therapy was not associated with significant complications. No perforations occurred in the sclerotherapy groups. In one patient in the sham group, a perforation occurred together with rebleeding. This patient was managed successfully by operation.

\section{Discussion}

Upper gastrointestinal haemorrhage from peptic ulcers remains a medical problem with considerable mortality. Continued bleeding or rebleeding of ulcers after hospital admission is associated with an appreciable increase in mortality." Early diagnostic endoscopy not only allows identification of the bleeding source but also predicts rebleeding. ${ }^{2}$ The presence of a protruding vessel in the centre of an ulcer crater 
carries a $50 \%$ risk of rebleeding. ${ }^{89}$ We chose this subset of patients to study the efficacy of injection therapy in preventing rebleeding. In this trial, injection therapy with absolute ethanol was better than sham therapy in preventing the recurrence of bleeding from peptic ulcers presenting with non-bleeding visible vessels seen at emergency endoscopy. The lack of significance $(p=0.07)$ is probably the result of a type II error. This therapy decreased transfusion requirements significantly. Epinephrinepolidocanol injection, however, did not decrease the rebleeding rate significantly. After two therapy sessions absolute ethanol injection resulted in a $88 \%$ definitive haemostasis rate compared with a $68 \%$ rate with epinephrinepolidocanol injections. This difference, as well as the difference in emergency surgery rates, was not significant.

In this study the overall outcome of the patients is remarkable. The fact that elective sclerotherapy for rebleeding in the sham group still resulted in a $73 \%$ haemostasis rate (eight of 11) comparable with the final haemostasis rate the other injection groups suggests that the time of endoscopic haemostasis is not critical and that this therapy can be just as efficacious given later on. If the vessel can be closed by sclerosant injection, haemostasis will be definitive irrespective of the number of bleeding episodes or the severity of the bleeding.

Absolute ethanol seems the more effective sclerosant. The results of epinephrinepolidocanol injection are disappointing in this study when compared with a former trial. ${ }^{4}$ In the present study the epinephrine-polidocanol group contained those patients with the worst bleeding, with 10 of 25 patients admitted in shock. Other trials comparing endoscopic modalities for haemostasis have been published. We showed $^{+}$that injection with epinephrine followed by polidocanol is as effective as injection of epinephrine followed by Yag laser. Loizou and Bown ${ }^{13}$ showed that injection of epinephrine alone has a similar efficacy to epinephrine followed by laser.

In a prospective randomised trial involving 64 patients with bleeding ulcers Balanzo et $a l^{14}$ compared injection therapy using epinephrine with injection of epinephrine plus thrombin. The addition of thrombin to epinephrine did not improve the results of therapy.

Laine, ${ }^{15}$ in a trial comparing injection therapy with absolute ethanol with multipolar electrocoagulation (MPEC), found both methods to be equally effective and safe for controlling active bleeding from peptic ulcers or preventing rebleeding from ulcers with a non-bleeding visible vessel.

Chung et $a l,{ }^{16}$ in a prospective randomised trial, compared the efficacy of endoscopic epinephrine injection and heater probe in actively bleeding peptic ulcers. Bleeding was initially better controlled with epinephrine injection $(96 \%)$ than with heater probe $(83 \% ; \mathrm{p}<0.05)$ but the outcome was similar in both groups. In the heater probe group there were two perforations.

In a randomised controlled trial ${ }^{17}$ comparing absolute alcohol injection with heater probe for the treatment of bleeding and non-bleeding vessels from peptic ulcers, Lin et al found the heater probe to be more effective than injection. In this trial emergency surgery rates and mortality were lowered by both techniques compared with control subjects.

The present study confirms that injection therapy is safe, although isolated cases of gastric wall necrosis ${ }^{18}{ }^{19}$ and even mortality because of injection have been reported. ${ }^{20}$

It is concluded that repeated absolute ethanol injection is an effective way of achieving endoscopic haemostasis. Absolute ethanol seems more effective than epinephrine-polidocanol.

1 Chung SCS, Leung JWC, Steele RJC, Crofts TJ, Li AKG Endoscopic injection of adrenaline for actively bleeding ulcers: a randomised trial. BMF 1988; 296: 1631-3.

2 Panes J, Forné M, Marco C, Viver J, Garcia-Olicones E, Garau $J$. Controlled trial of endoscopic sclerosis in bleeding peptic ulcers. Lancet 1987; ii: 1292-4.

3 Balanzo J, Sainz S, Such J, Espinos JC, Guarner G, Casso X, et al. Endoscopic hemostasis by local injection of Epinephrine and polidocanol in bleeding ulcer. A prospective randomized trial. Endoscopy 1988; 20: 289-91.

4 Rutgeerts P, Broeckaert L, Janssens J, Vantrappen G, Coremans G, Hiele $M$. Comparison of endoscopic polidocanol injection and Yag laser therapy for bleeding peptic ulcers. Lancet 1989 ; i: 1164-7.

5 Pascu O, Drãghici A, Acalovehi I. The effect of endoscopic hemostasis with alcohol on the mortality rate of non variceal upper GI hemorrhage. A randomized prospective study. Endoscopy 1989; 21: 53-5.

6 Rajgopal C, Palmer KR. Endoscopic injection sclernsis: effective treatment for bleeding peptic ulcer. Gut 1991; 32 727-9.

7 Oxner RBG, Simmonds NJ, Gertner DJ, Nightingale JMD, Burnham WR. Controlled trial of endoscopic injection treatment for bleeding from peptic ulcers with visible vessels. Lancet 1992; 339: 966-8.

8 Storey DW, Bown SG, Swain CP, Salmon PR, Kirkham JS, Northfield TC. Endoscopic prediction of recurrent bleeding in peptic ulcers. N Englf Med 1987; 305: 915-6.

9 Swain CP, Storey DW, Bown SG, Heath J, Mills TN, Salmon $\mathrm{PR}$, et al. Nature of the bleeding vessel in recurrently bleeding gastric ulcer. Gastroenterology 1986; 90: 595-608.

10 Young MJ, Bresnitz EA, Strom BL. Sample size nomograms for interpreting negative clinical studies. Ann Intern Med for interpreting neg.

11 Schiller KFR, Truelove SC, Williams GD. Haematemesis and melaena, with special reference to factors influencing the outcome. BMF 1970; ii: 7-14.

12 Silverstein FE, Gilbert DA, Tedesco FJ. The national ASGE survey on gastrointestinal bleeding. II Clinical prognostic factors. Gastrointest Endosc 1981; 27: 80-93.

13 Loizou LA, Bown SG. Endoscopic treatment for bleeding peptic ulcers: randomized comparison of adrenaline injection and adrenaline injection $+\mathrm{Nd}$ :Yag laser. Gut 1991; 12: $1100-3$

14 Balanzo J, Villanueva C, Sainz S, Espinos JC, Mende\% C, Guarner $\mathrm{C}$, et al. Injection therapy of bleeding peptic ulcer. A prospective randomized trial using Epinephrine and

15 Laine L. Multipolar electrocoagulation versus injection therapy in the treatment of bleeding peptic ulcers. A prospective randomized trial. Gastroenterolog 1 1990; 99: $1303-6$

16 Chung SCS, Leung JWC, Sung JY, Lo KK, Li AKC Injection or heat probe for bleeding ulcer. Gastroenterology 1991; 100: 33-7.

17 Lin HJ, Lee FY, Kang WM, Tsai YT, Lee SD, Lee CH. Hea probe thermocoagulation and pure alcohol in massive peptic ulcer haemorrhage: a prospective randomized controlled trial. Gut 1990; 31: 753-7.

18 Chester JF, Hurley PR. Gastric necrosis: a complication of endoscopic sclerosis for bleeding peptic ulcer. Endoscopy $1990 ; 22: 287-8$

19 Loperfido S, Patelli G, La Torre I. Extensive necrosis of gastric mucosa following injection therapy of bleeding peptic uastric mucosa following injection

20 I evy J, Khakoo S, Barton R, Vicary R. Fatal injection sclerotherapy of a bleeding ulcer. Lancet 1991; 337: 504 . 